\title{
Osmolality Unit
}

National Cancer Institute

\section{Source}

National Cancer Institute. Osmolality Unit. NCI Thesaurus. Code C67426.

A unit for concentration measurement of osmotically active particles expressed as a

number of osmoles of solute per kilogram of solvent. 